\title{
TRANSFERÊNCIA DE RENDA NO BRASIL
}

\author{
MARCELO MEDEIROS, \\ TATIANA BRITTO E \\ FÁBIO SOARES ${ }^{1}$
}

\begin{abstract}
RESUMO
O artigo apresenta os dois principais programas focalizados de transferência de renda no Brasil, o Benefício de Prestação Continuada (BPC) e o Programa Bolsa Família (PBF). Discute aspectos institucionais dos programas, sua sustentabilidade de longo prazo, o público atendido e o grau de focalização, a necessidade de condicionalidades, os efeitos das transferências sobre a participação no mercado de trabalho e sobre a contribuição para a previdência. Conclui que os programas estão cumprindo a função a que se destinam, têm bom desempenho em comparações internacionais e apresentam custo compatível com a capacidade orçamentária brasileira sem, aparentemente, ter efeitos negativos sobre os incentivos para o trabalho e a contribuição previdenciária.
\end{abstract}

PALAVRAS-CHAVE: Transferência de renda; assistência social; pobreza; desigualdade social; Bolsa Família; BPC.

\section{SUMMARY}

The article describes several characteristics of the two most important targeted cash transfer programs in Brazil, the Continuous Cash Benefit (BPC) and the Bolsa Família Program (PBF), and discusses their institutional aspects, long term sustainability, beneficiaries and levels of targeting. It also addresses the need of feedback conditions, the effects of the transfers on the participation in the labor market and on the contributions for the pensions system. The conclusion is that, on the one hand, the programs are accomplishing the goals they were designed to, under costs which are compatible with the Brazilian budgetary capacity; on the other hand, they apparently have no negative effects on incentives to work and contributions to the pensions system.

KEYWORDS: Cash transfers; social assistance; poverty; social inequality; Bolsa Família; BPC.

[1] Os autores agradecem os comentários e sugestões de Francesca Bastagli, Rafael Ribas e Rodolfo Hoffmann à primeira versão do texto.
O Brasil observou, recentemente, uma expansão considerável de políticas públicas de transferência direta de renda para a população pobre. Hoje, o país tem dois grandes programas dessa natureza: o Benefício de Prestação Continuada (conhecido como BPC-Loas ou, simplesmente, BPC) eo Programa Bolsa Família (PBF). Ambos são objeto de um debate quanto à efetividade, à sustentabilidade e aos possíveis impactos adversos. O objetivo deste artigo é reunir evidências que contribuam para responder a algumas questões recorrentes neste debate. 
O BPC é uma transferência mensal de renda destinada a pessoas com deficiência severa, de qualquer idade, e idosos maiores de 65 anos, em ambos os casos com renda familiar per capita inferior a um quarto de salário mínimo ( $\mathrm{R} \$ 87,50$ em outubro de 2006). O direito a um salário mínimo mensal para essas pessoas foi estabelecido na Constituição de 1988 e regulamentado pela Lei Orgânica da Assistência Social (Loas), em 1993. O início da implementação do BPC, em 1995, deu-se no contexto de administração conjunta da previdência e da assistência social no governo federal. Embora a coordenação do programa hoje seja feita pelo órgão gestor da assistência social (o Ministério do Desenvolvimento Social e Combate à Fome - MDS), o benefício é solicitado em agências do Instituto Nacional do Seguro Social (INSS) e a seleção dos beneficiários é feita em boa parte por médicos peritos da Previdência, que avaliam os deficientes que requerem o benefício quanto ao grau de incapacidade para a vida independente e o trabalho. Por essas razões, a operacionalização é feita pelo INSS e por sua agência de processamento de dados, a Dataprev. O BPC não exige contrapartidas de comportamento - as chamadas condicionalidades - de seus beneficiários.

O Programa Bolsa Família (PBF) é um programa de transferência mensal de renda que surgiu, no final de 2003 , a partir da unificação de uma série de programas preexistentes, bastante inspirado pelo programa de renda mínima vinculado à educação, o Bolsa Escola. O Bolsa Família deve atender a famílias cuja renda familiar per capita seja inferior a $\mathrm{R} \$ 60$ mensais e famílias de gestantes, nutrizes, crianças e adolescentes de até 15 anos cuja renda per capita seja inferior a $\mathrm{R} \$ 120$ (valores de outubro de 2006). Foi criado por medida provisória, posteriormente convertida em lei. A seleção dos beneficiários é, em geral, realizada pelos órgãos municipais de assistência social, ficando a gerência do programa a cargo do MDS e as operações de pagamento sob responsabilidade da Caixa Econômica Federal. O recebimento das transferências é condicionado a contrapartidas comportamentais nas áreas de educação e saúde - essencialmente: freqüência à escola, vacinação de crianças e acompanhamento prée pós-natal de gestantes e nutrizes - de acordo com a composição das famílias beneficiárias.

\section{PÚblico atendido}

Os programas se destinam a públicos distintos e cada um deles possui mecanismos administrativos próprios de identificação e seleção de beneficiários. Ambos já foram criticados por erros graves de seleção. A maior parte dessas críticas teve caráter casuístico, não se fundamentando sobre evidências empíricas generalizáveis e sistemáticas. Na prática, limitaram-se a apontar uma ou mais famílias beneficiárias com 
[2] Soares, F.V.e outros. "Programas de transferência de renda no Brasil: impactos sobre a desigualdade". Ipea, 2006 (Texto para Discussão, n. $1.228)$. renda acima das respectivas linhas de corte e a fazer inferências, com base nesses desvios, sobre todo o funcionamento dos programas.

No entanto, casos isolados não são evidências adequadas para avaliar programas que, juntos, afetam diretamente quase 14 milhões de famílias. Identificar o público de fato beneficiado por esses programas é crucial para determinar em que medida seus objetivos estão sendo atingidos e o que pode ser feito para melhorá-los. Com a divulgação dos resultados da Pesquisa Nacional por Amostra de Domićlios (Pnad) de 2004, tornaram-se possíveis os primeiros estudos sobreo assunto com base em dados com representatividade nacional.

Os dados da Pnad 2004, no entanto, apresentam algumas limitações. Desde o início dos programas de transferência de renda, o IBGE tem captado esses recursos na categoria de "outros rendimentos", na qual também são incluídos juros de aplicações financeiras, dividendos eo seguro-desemprego.Aexistência de um suplemento especial sobre programas de transferência de renda na Pnad 2004 não alterou esse quadro, uma vez que o questionário suplementar foi associado ao questionário do domićlio, e não ao questionário individual. Tampouco foi criada uma entrada especial para o rendimento proveniente das transferências, fazendo com que não seja possível identificarquem é o titular do benefício, nem separar a renda da transferência dos "outros rendimentos" de maneira direta. Num texto elaborado no Ipea, "Programas de transferência de renda no Brasil:impactos sobre a desigualdade", 2 é desenvolvida uma metodologia para fazer essa separação de maneira aproximada, de modo a permitir avaliar dois aspectos: 1) a capacidade da Pnad de captaressas transferências vis-à-vis os registros administrativos e 2) o grau de focalização das transferências.

Embora não reproduza bem os números absolutos dos registros administrativos dos diversos programas de transferência que estavam sendo unificados no Bolsa Família, a Pnad representa bem, em termos relativos, a distribuição regional dos beneficiários e suas características. Em nível agregado, o BPC também é bem captado em termos relativos, mas não em termos absolutos. Entretanto, entre os idosos beneficiários do BPC há sobrestimação da proporção de beneficiários na região Nordeste e subestimação na região Sudeste, em relação aos dados dos registros administrativos. Uma possível explicação para esse fenômeno pode ser a confusão, por parte dos beneficiários ou dos respondentes dos questionários nos domicílios, entre o BPC e outros benefícios previdenciários, uma vez que todos são operacionalizados pelo INSS. É possível, portanto, que uma parte significativa do BPC esteja sendo captada nas entradas de aposentadorias e pensões.

Apesar dessas dificuldades, uma análise da distribuição de ambos os programas na população indica que o BPC e o Bolsa Família estão cumprindo, em boa medida, seus propósitos e sendo efetivamente 
direcionados à população mais pobre. O gráfico 1 abaixo mostra a distribuição das transferências nos distintos estratos da população. Nele é possível observar que tanto o BPC ambos os programas apresentam um bom nível de focalização nos pobres.

\section{GRÁFICO I}

Incidência da renda dos benefícios na população ordenada segundo nível de renda líquida (excluído o benefício)

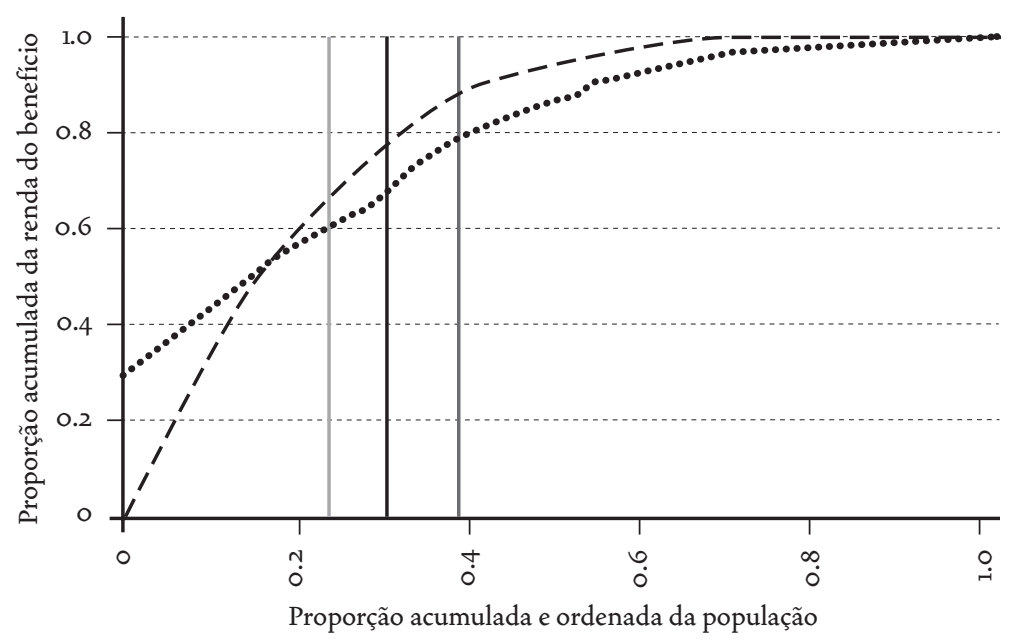

$\begin{array}{llr}\mathrm{R} \$ 65 \text { (critério BPC) } & -1-\mathrm{PBF} & \cdots \cdots \\ \mathrm{R} \$ 130 \text { (pobreza) } & & \mathrm{R} \$ 100 \text { (critério Bolsa Família) }\end{array}$

Fonte: Soares etal.(2006).

No entanto, a partir dos próprios resultados da Pnad, é possível notar que parte razoável dos beneficiários encontra-se acima dos níveis de renda delimitados pelos programas - um quarto de salário mínimo ( $\mathrm{R} \$ 65$ em setembro de 2004, mês de referência da Pnad), no caso do BPC, e R $\$ 50$ ou $\mathrm{R} \$ 100$, valores de corte do Programa Bolsa Família à época. Na verdade, cerca de $38 \%$ da renda do BPC vai para beneficiários em famílias com renda per capita superior a $\mathrm{R} \$ 65$, enquanto $21 \%$ da renda do Bolsa Família vai para beneficiários em famílias com renda percapita superior a $\mathrm{R} \$ 100$. Isso pode, de fato, ser interpretado como erros de focalização? Em caso afirmativo, o que está por trás desses desvios? Mais ainda, em que medida seria possível reduzi-los? Ainda que essas questões sejam difíceis de responder, elas permitem desenvolver argumentos sobre os limites de qualquer mecanismo de focalização. Dois fatores devem ser considerados nesse debate. O primeiro refere-se à flutuação da renda das famílias ao longo do tempo; o segundo, aos erros intrínsecos à seleção de beneficiários em um programa focalizado.

Há várias razões pelas quais as rendas das famílias flutuam. Rotatividade no emprego, sazonalidade da economia, choques 
externos positivos e negativos, mudanças na composição e organização das famílias, entre outros motivos, fazem com que a renda familiar per capita, especialmente daqueles inseridos no mercado de trabalho informal, varie ao longo do tempo. Como os programas não possuem um ciclo permanente de revisão - e não seria nem viável nem desejável fazê-lo - é compreensível que parte da população esteja acima dos limites de corte adotados, ainda que, no momento da inclusão, estivessem cumprindo integralmente com todos os requisitos regulamentares.

Nem sempre é desejável que uma família seja retirada do programa por ultrapassar o patamar de renda usado para incluir beneficiários. O risco de desincentivos ao trabalho - relacionados à chance de perda do benefício, e não ao aumento de rendimentos - é um exemplo claro disso. Os membros de uma família ameaçada de exclusão caso sua renda aumente só têm incentivos para trabalhar se a renda adicional a ser obtida com esse trabalho for superior às transferências recebidas. Para esse caso típico, o programa deveria ter um patamar de renda de saída superior ao de entrada. Em casos semelhantes, é também necessário levar em conta a sustentabilidade das novas rendas. O programa assegura estabilidade de rendimentos, ao passo que isso não ocorre com muitos tipos de trabalho. Ao escolher entre aceitar ou não um novo trabalho, as pessoas levam em consideração, entre outras coisas, o risco de trocar as transferências estáveis do programa por rendas instáveis de um trabalho qualquer. Nessas situações também não seria desejável que ocorresse a cessação dos benefícios, uma vez que regras de interrupção desse tipo podem desestimular a inserção laboral.

Além disso, é preciso ter em conta que boa parte das inscrições para os programas de transferências passa por processos que, na prática, equivalem a uma estimativa de renda das famílias. No caso dos programas brasileiros, esse processo se baseia no cálculo da renda familiar per capita a partir da renda declarada no momento do cadastramento. Como toda estimativa, esta é sujeita a falhas que não se pode controlar facilmente.

Todo processo de seleção de beneficiários possui erros intrínsecos que são difíceis de evitar. Uma parte desses erros denota o dilema inevitável entre a utilização de critérios excessivamente rígidos na seleção, o que leva à exclusão de famílias que deveriam ser beneficiadas (erro de cobertura ou exclusão), ou muito lassos, o que leva à inclusão de famílias que não deveriam ser beneficiadas (erro de vazamento ou inclusão). É o que alguns chamam de cobertor curto: cobertos os pés, fica necessariamente de fora a cabeça, e vice-versa. Parte dos desvios assim como parte das falhas de cobertura - deve-se a esse tipo de erro intrínseco à seleção. 
A despeito das dificuldades de alcançar de fato os extremamente pobres e excluídos, nas fases iniciais de um programa, quando os níveis de cobertura são reduzidos, é relativamente mais simples manter as transferências focalizadas em famílias que não se encontrem acima dos limites de elegibilidade. À medida que a cobertura cresce e os mais pobres são atendidos, torna-se cada vez mais difícil evitar que famílias logo acima dos limites de elegibilidade sejam incluídas. Todavia, a inclusão de famílias logo acima desses limites deve ser entendida como um problema secundário, pois a intensidade desse tipo de desvio é reduzida. O problema principalé, na verdade, a exclusão de beneficiários potenciais devido à inclusão de famílias muito acima da linha de corte.

Nesse sentido, vale a pena retornar aos resultados do Gráfico 1. Observe-se que a incidência de beneficiários acima dos limites de corte do BPC e do Bolsa Família não é desprezível. Porém os desvios ocorrem para famílias que estão pouco acima desses limites. Em outras palavras, ao mesmo tempo que a incidência dos desvios é razoável, sua intensidade é muito pequena. Desvios de grande intensidade são raros: menos de $12 \%$ da renda do Bolsa Família e $20 \%$ da renda do BPC vão para beneficiários em famílias com renda percapita superior a $\mathrm{R} \$ 130$ em 2004.

Especificamente no caso do BPC, também deve ser mencionado que há beneficiários vivendo em famílias cuja renda é superior ao limite definido no programa por força de determinação judicial. $O$ pressuposto constitucional do BPC baseia-se em princípios gerais sobre o necessário para a subsistência. A definição dos critérios operacionais de elegibilidade é feita por leis ordinárias e por normas do Executivo, algumas delas questionadas, com sucesso, por ações judiciais que inovam ou atualizam a interpretação dos princípios da Constituição. As contestações mais típicas elevam o limite de corte do BPC de um quarto a meio salário mínimo, por considerar este último um patamar de pobreza socialmente reconhecido, ou, ainda, autorizam o cômputo da renda familiar calculada sem despesas com medicamentos, em uma tentativa de diferenciar necessidades, algo que o desenho do BPC e do PBF ainda não é capaz de fazer a contento. Além disso, o conceito de família do BPC³ não é o mesmo conceito do PBF, nem da Pnad. Dessa maneira, no cálculo da renda per capita utilizado no Gráfico 1, a renda de filhos ou agregados maiores de 21 anos é considerada, enquanto essa mesma renda é excluída para a avaliação da elegibilidade ao BPC.

Existem, também, desvios oriundos de problemas no processo de seleção dos beneficiários, decorrentes desde a utilização de ferramentas inadequadas para identificá-los até fraudes deliberadamente impostas ao sistema. Ferramentas melhores, tais como um questio-

\footnotetext{
[3] Por influência da administração do INSS, a definição de família no BPC limita-se ao conjunto de familiares autorizados a receber pensões em caso de falecimento do beneficiário da seguridade, qual seja: pais, esposo ou companheiro e filhos ou irmãos menores de 21 anos ou inválidos, desde que vivam em coabitação. Já o PBF entende como família toda unidade nuclear que forme um grupo doméstico em coabitação regular.
} 
[4] Apresentado em Soares, S. e outros. "Conditional cash transfers in Brazil, Chile and Mexico: Impacts upon inequality".2007 (International Poverty Centre Working, paper n.35). nário aprimorado de cadastramento e estudos locais que balizem as avaliações dos assistentes sociais, médicos peritos e outros profissionais envolvidos na seleção dos beneficiários do BPC e do PBF, indiscutivelmente ajudariam a melhorar a focalização dos programas. As fraudes, por sua vez, requerem mecanismos de verificação de outras informações sobre os beneficiários cadastrados, como o recebimento de benefícios previdenciários, comparação de cadastros com registros de empregadores (como a Relação Anual de Informações Sociais - Rais), revisão periódica (conforme prevê a regulamentação do BPC) e, nos casos em que se apliquem, medidas punitivas aos fraudadores.

Há evidências de melhorias nos mecanismos de seleção e controle dos programas. Nesse campo, o Bolsa Família tem avançado mais rapidamente que o $\mathrm{BPC}$, com o estabelecimento de rotinas de verificação da consistência cadastral e a modificação dos formulários de inscrição (instrumentos que, ao que tudo indica, serão adotados, no futuro próximo pelo BPC). A criação de uma rede pública de fiscalização em 2005, envolvendo ministérios públicos, Corregedoria-Geral da União (CGU) e Tribunal de Contas da União (TCU), também poderá ser uma medida importante no combate às fraudes. Da mesma forma, o aperfeiçoamento de mecanismos de participação e controle social no nível municipal e o estabelecimento de canais de comunicação direta entre beneficiários e potenciais beneficiários com as instâncias de gestão do PBF poderá contribuir para difundir informações e minorar os erros de focalização.

É sempre possível tentar obter informações mais precisas e usar ferramentas mais sofisticadas para selecionar beneficiários. Cabe perguntar, porém, se já não alcançamos um patamar razoável de focalização. Para isso, é conveniente comparar o desempenho dos programas brasileiros com aquele de programas considerados exitosos em outros países. O Gráfico 24 faz essa comparação, trazendo indicações sobre o desempenho de programas de transferência de renda similares, implementados no Chile e no México.

O que o Gráfico 2 permite concluir é que os programas brasileiros atingem seu público-alvo de maneira aproximadamente tão eficaz quanto os programas semelhantes de países vizinhos, muitas vezes apresentados como modelos de boas práticas. O México e o Chile, que usam questionários extensos e completos para identificar beneficiários, conseguem um resultado próximo ao obtido pelo processo de seleção altamente descentralizado do Brasil. Cabe lembrar que procedimentos centralizados e complexos podem reduzir a possibilidade de controle social dos programas e que controles extremamente rigorosos de focalização e ciclos mais curtos de revisão de benefícios e implicam, em geral, custos administrativos mais elevados. 


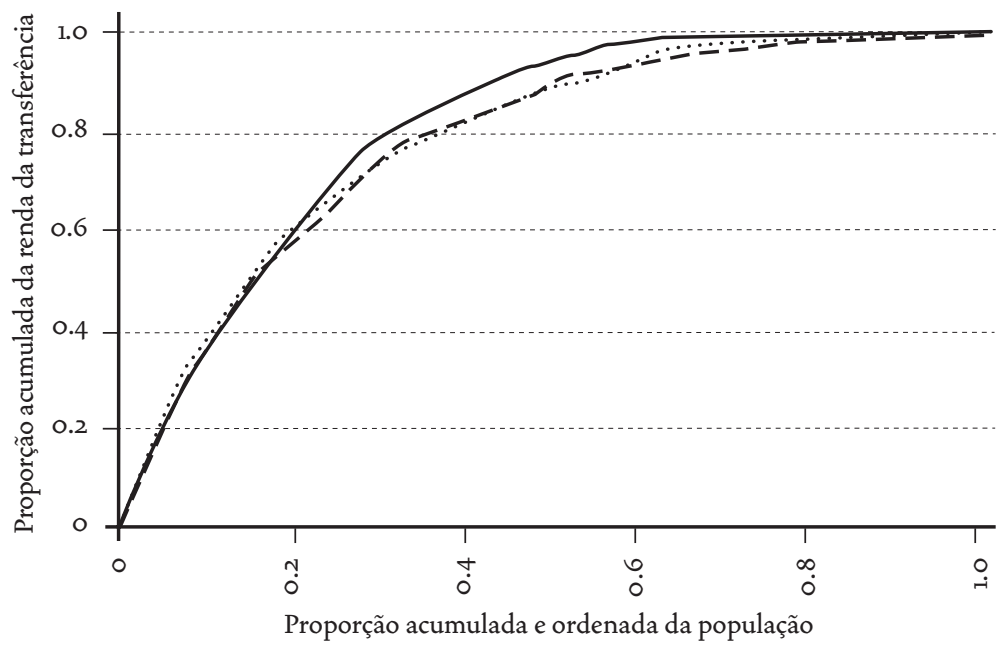

— Bolda Família - Brasil - - Oportunidades - México … Chile Solidário-Chile

Fonte: Soares e outros. Conditional cash transfers in Brazil, Chile and Mexico:Impacts upon inequality. 2007.

Com isso, não se pretende afirmar que não devam ser feitos esforços para o constante aprimoramento dos programas brasileiros, inclusive no sentido de minorar os erros de seleção. Mas esses esforços devem sempre ser norteados por análises de custo-benefício que os justifiquem e pela diretriz de minimizar, tanto quanto seja razoável, a exclusão de beneficiários que teriam direito aos programas.

\section{CONDicionalidades}

Uma das propaladas inovações do Programa Bolsa Família, assim como de seus antecessores Bolsa Escola e Bolsa Alimentação, diz respeito a um desenho que se propõe a aliar dois objetivos centrais: o alívio da pobreza no curto prazo, por meio das transferências de renda, e o combate a sua transmissão intergeracional, por meio de condicionalidades voltadas para incentivar as famílias a realizar investimentos em capital humano. Adicionalmente, a exigência de condicionalidades, também chamadas de contrapartidas ou co-responsabilidades das famílias, tem como objetivo incentivar a demanda por serviços sociais como saúde e educação e ampliar o acesso da população mais pobre a direitos sociais básicos, incentivando expansões e melhorias na oferta desses serviços.

A mais conhecida condicionalidade do Bolsa Família é a de freqüência escolar das crianças. O programa exige que as crianças estejam presentes em $85 \%$ das aulas e instituiu um sistema de acompa- 
[5] Centro de Desenvolvimento e Planejamento Regional (Cedeplar). Projeto de avaliação do impacto do programa Bolsa Família - relatório analítico final. 2006 (mimeo).

[6] Carvalho Filho, I. E. Household income as a determinant of child labor and school enrollment in Brazil: Evidence from a social security reform. 2001 (mimeo).

[7] Reis, M. C., Camargo, J. M. “Rendimentos domiciliares com aposentadorias e pensões e as decisões dos jovens quanto à educação e à participação na força de trabalho". Ipea, 2007 (Texto para Discussão,n.1.262). nhamento que é alimentado pelos municípios e transmitido ao governo federal, a fim de que se apliquem advertências e sanções no caso de descumprimento. Trata-se de uma inovação, uma vez que a exigência de controle de freqüência escolar, segundo a legislação, limitava-se a $75 \%$ das aulas e competia, apenas, aos estabelecimentos de ensino.

Do ponto de vista dos resultados, a necessidade e o impacto das condicionalidades são controversos. Se, desde a criação do sistema de acompanhamento da condicionalidade de educação, mais de 95\% daqueles que tiveram a freqüência escolar monitorada cumpriram a exigência estabelecida, é difícil afirmar se isso é resultado direto do controle de condicionalidades ou uma tendência independente desse controle.

Recente avaliação de impacto 5 traz alguns resultados preliminares sobre os efeitos do Bolsa Família sobre a educação. Os resultados observados indicam que as crianças atendidas pelo programa têm menor probabilidade de faltar um dia de aula por mês em comparação com crianças em domicílios similares que não recebem o benefício. Ademais, a probabilidade de as crianças beneficiárias abandonarem a escola também é menor. Entretanto, os efeitos observados sobre a educação podem estar sendo os mesmos de um programa sem condicionalidade, pois há indicações de que, mesmo na ausência de contrapartidas, programas de transferência de renda têm efeitos positivos sobre a escolaridade das crianças. Carvalho ${ }^{6}$ mostra que a aposentadoria rural não contributiva, ao incrementar a renda dos idosos, teve um efeito positivo sobre a matrícula das crianças do domicílio, particularmente de meninas entre 12 e 14 anos. Para estas, a taxa de não-matrícula caiu em 20\%. Com base em dados da Pnad, Reis e Camargo7 estimaram que um importante efeito relacionado a aposentadorias e pensões não condicionadas a contrapartidas é aumentar a probabilidade de freqüência à escola dos jovens.

Em muitos casos, as condicionalidades de saúde e educação apenas reforçam algo a que os pais já são obrigados - legal ou socialmente - a fazer por suas crianças: enviá-las à escola, vaciná-las e cuidar de sua saúde. Dessa maneira, não parece haver nenhuma novidade ou mesmo "intrusividade" nas condicionalidades — o que não significa que não possa haver excessos na forma de sua imposição.

Se as condicionalidades podem ser desnecessárias, o problema de sua existência pode residir nos custos que seu controle acarreta. Um sistema tempestivo e eficiente de monitoramento de condicionalidades em escala nacional pode implicar custos administrativos importantes, não só para o governo federal, mas, principalmente, para os municípios, encarregados de alimentá-lo periodicamente. No entanto, uma avaliação cuidadosa dos benefícios e custos de um controle homo- 
gêneo para todo o país ainda precisa ser feita para que haja uma idéia melhor da conveniência desses mecanismos. Além disso, ao gerarinformações sobre possíveis omissões nas ações de saúde ou na freqüência escolar, o monitoramento de condicionalidades pode funcionar como um instrumento para alertar o poder público sobre famílias em situações de maior vulnerabilidade, que demandam atenção específica, além de identificar gargalos na oferta desses serviços. Em poucas palavras, não se sabe ao certo quão necessárias são as condicionalidades, quanto se gasta para controlá-las e o que exatamente se ganha com isso.

Se as condicionalidades de saúde e educação já são algo que os pais devem fazer com ou sem o benefício, por que elas são tão importantes no debate? Talvez porque a discussão sobre a necessidade das condicionalidades também tenha como pano de fundo questões políticas e juízos de valor. As condicionalidades em parte atendem às demandas daqueles que julgam que ninguém pode receber uma transferência do Estado - especialmente os pobres - sem prestar alguma contrapartida direta. As condicionalidades seriam algo equivalente ao "suor do trabalho"; sem essa simbologia, o programa correria o risco de perder apoio na sociedade. Essa característica não é uma idiossincrasia do Bolsa Família, pois aparece também em vários programas implementados em outros países ${ }^{8}$. A existência de programas de transferência condicionada de renda tem que ser negociada a partir da imposição de condicionalidades de educação e saúde e, em alguns casos, de contrapartidas de trabalho, independentemente de avaliações objetivas da relação entre custo e beneficio dessas ações. A discussão sobre a transformação do Bolsa Família em um programa sem condicionalidades ou sua manutenção no desenho atual tem sido evitada por razões fundamentalmente políticas.

\section{EFEITOS SOBRE A OFERTA DE TRABALHO}

O Bolsa Famíliaé concedido a famílias que estão ou poderiam estar no mercado de trabalho, mas, ainda assim, têm renda muito baixa. Por esse motivo encontra-se sujeito à crítica de que as transferências de renda desestimulam o trabalho. A crítica se baseia na idéia, bastante plausível, de que, à medida que atingem certo nível de renda, as pessoas têm incentivos para trabalhar menos ou deixar de trabalhar.

O que torna essa crítica mal fundamentada é o nível a partir do qual as transferências resultariam em desestímulo relevante à participação no mercado de trabalho. Ainda não existem resultados robustos sobre o tema, mas é possível discutir alguns resultados preliminares e especular um pouco sobre sua razoabilidade. O Bolsa Família transfere entre $\mathrm{R} \$ 15$ e R $\$ 95$ a famílias de renda extremamente baixa. Embora a importância do programa para a melhoria das condições de vida das
[8] Handa, S., Davis, B. “The experience of conditional cash transfers in Latin America and the Caribbean". Development Policy Review, Oxford, UK: Blackwell Publishing, vol. 24, n.5, 2006. 
famílias beneficiárias seja inegável, representando aumento de cerca de $11 \%$ em sua renda, o benefício médio gira em torno de $R \$ 60$, valor que não parece suficiente para que os beneficiários deixem de trabalhar, a não ser em casos de trabalhos extremamente mal-remunerados, instáveis ou mesmo insalubres.

As transferências diminuem a operosidade dos trabalhadores? É bem possível que elas tenham o efeito contrário à medida que conferem aos trabalhadores pobres recursos que lhes permitem ultrapassar certas barreiras de entrada em segmentos mais vantajosos do mercado de trabalho. Um exemplo simples ajuda a entender essa idéia.

Imagine-se um trabalhador autônomo, um vendedor ambulante. Uma barreira para que esse vendedor expanda seus negócios e envolva neles outros membros de sua família é o acesso a capital de giro para comporestoques. Se a família dessevendedor recebe as transferências, o dinheiro pode ter um efeito similar ao da abertura de uma linha de microcrédito - sem, evidentemente, os aspectos relacionados à necessidade de repagamento. Ora, se o governo abaixar impostos, juros ou conceder crédito para os empresários no outro extremo da distribuição de riqueza, eles vão se acomodar e parar de trabalhar? Em geral, a resposta para essa pergunta é negativa. Deve-se esperar que os microempresários pobres se comportem da mesma maneira que seus pares ricos. As transferências, portanto, podem, na verdade, aumentar os níveis de ocupação dos trabalhadores.

O fato é que tomar as transferências como um desestímulo ao trabalhoéuma idéia que pode ser fundamentada em preconceitos, mas não se apóia em evidências empíricas. Dados recentes do Instituto Brasileiro de Geografia e Estatística (IBGE) mostram que pessoas que vivem em domicílios onde há beneficiários do Bolsa Família trabalham tanto ou mais que as outras pessoas com renda familiar per capita similar. Enquanto a taxa de participação no mercado de trabalho das pessoas em domicílios com beneficiários é de $73 \%$ para o primeiro décimo mais pobre da distribuição, $74 \%$ para o segundo e $76 \%$ para o terceiro, a mesma taxaéde $67 \%, 68 \%$ e $71 \%$, respectivamente, para as pessoas que vivem em domićlios sem beneficiários.

Eventuais efeitos negativos sobre a oferta de trabalho para grupos específicos de trabalhadores não devem ter uma leitura necessariamente negativa. Famílias extremamente pobres tendem a intensificar a participação de mulheres, crianças e jovens no mercado de trabalho, quase sempre em ocupações precárias e mal remuneradas. Nesses casos, alguma redução da participação desses indivíduos no mercado laboral, devido ao recebimento do Bolsa Família, pode ser vista de maneira positiva.

$\mathrm{Na}$ verdade, observando-se de forma desagregada a probabilidade de ser parte da população economicamente ativa (entre 18 e 65 anos), 
para homens e mulheres separadamente, e adicionando-se as classificações de chefes de domicílio e cônjuges à análise, percebem-se algumas diferenças.Analisando-se os dados da Pnad 2004 com um modelo probit estimado para os três primeiros décimos da distribuição — os $30 \%$ mais pobres - e que controla os efeitos de idade e composição familiar (número de crianças e idosos no domicílio), foi possível estimar que a oferta de trabalho de apenas uma das quatro combinações do modelo (mulheres chefes, mulheres cônjuges, homens chefes e homens cônjuges) é afetada negativamente pelo Bolsa Família. Apenas as mulheres chefes que recebem o programa têm probabilidade menor ( $e$ estatisticamente significante) de participar do mercado de trabalho do que as mulheres chefes que não recebem a transferência. Para os outros três grupos, o programa não tem impacto algum sobre a oferta de trabalho dos beneficiários quando comparados com grupos similares.

$\mathrm{Na}$ mesma linha, resultados da linha de base da avaliação de impacto do Bolsa Família9 mostram um efeito positivo do programa sobre a oferta de trabalho. De acordo com os dados da pesquisa, adultos em domicílios com beneficiários do Bolsa Família têm uma taxa de participação 3\% maior do que adultos em domicílios não beneficiários. Além disso, esse impacto é maior entre as mulheres, $4 \%$, do que entre os homens, $3 \%$. O programa também diminui as chances de uma mulher empregada sair do seu emprego em $6 \%$.

O que os dados mostram é que o "ciclo da preguiça" motivado pelas transferências é uma falácia. Quem, de fato, apresenta uma taxa de participação menor no mercado de trabalho, quando comparadas a indivíduos em situação semelhante, são aquelas pessoas do último décimo da distribuição e que possuem renda na categoria de "outros rendimentos” da Pnad. Nessa posição da distribuição, é provável que essa categoria seja composta basicamente de juros de aplicações financeiras. Ou seja, os rentistas ricos trabalham menos que os nãorentistas ricos. A maioria dos pobres é muito trabalhadora, conforme mostram os dados do IBGE. Talvez seja desnecessário enfatizar que, geralmente, os pobres não deixam de trabalhar por decisões livres e espontâneas, e sim porque não têm emprego em condições aceitáveis.

\section{IMPREVIDÊNCIA}

Se o Bolsa Família é mais freqüentemente acusado de gerar desincentivos ao trabalho, o BPC costuma ser criticado por incentivar a evasão das contribuições previdenciárias. A crítica, nesse caso, é que o BPC substitui com um programa assistencial parte da seguridade social de base contributiva. O raciocínio detrás da crítica é que, se as pessoas receberão com o BPC o mesmo que receberiam pelo sistema previdenciário, não há motivo para contribuírem para a previdência social pública.

\footnotetext{
[9] Centro de Desenvolvimento e Planejamento Regional (Cedeplar). Projeto de avaliação do impacto do programa Bolsa Família - relatório analitico final. 2006 (mimeo).
} 
Essa é uma crítica de caráter ainda especulativo. Não existe, no Brasil, nenhum estudo rigoroso e abrangente sobre as motivações da contribuição para o sistema previdenciário, bem como não há evidências que comprovem que a expectativa de recebimento do BPC está relacionada a um comportamento imprevidente ou evasivo de potenciais contribuintes da seguridade social. Além disso, o impacto pode existir, mas ser irrelevante para o sistema previdenciário como um todo.A validade da crítica depende, portanto, de que o comportamento imprevidente, além de existir, seja de boa magnitude.

A hipótese lançada nesse tipo de crítica pode ser plausível, mas seria razoável? Vejamos. As contribuições previdenciárias não são progressivas. Logo, em termos de bem-estar, o ônus de uma contribuição previdenciária é muito maior para os mais pobres, mesmo quando ricos e pobres contribuem com a mesma proporção de seus rendimentos. Em outras palavras, contribuir com 10\% dos rendimentos representa um esforço muito maior para os mais pobres do que para os mais ricos. Na verdade, para todas as pessoas de baixa renda, realizar a contribuição previdenciária implica abdicar de uma renda muito importante para elas. O contrapeso dessa importância é o ônus esperado presente e futuro - de não poder contar com a renda do trabalho. Se esse ônus for alto o suficiente para compensar o ônus da perda de parte da renda presente, compensa formar uma poupança, privada ou pública, que possa ser usada quando não for mais possível trabalhar.

A poupança previdenciária geralmente ocorre por imposição das contribuições previdenciárias obrigatórias aos assalariados. Proporcionalmente, a contribuição voluntária entre trabalhadores informais ou ocupados por conta própria, de baixa renda, sempre foi muito menor. Segundo os dados da Pnad, entre 1992 e 2005 a proporção de trabalhadores sem carteira contribuindo para a previdência social aumentou de $6 \%$ para $11 \%$, enquanto a proporção de contribuintes trabalhadores por conta própria caiu de $20 \%$ para $15 \%$. Se observarmos apenas os trabalhadores por conta própria e sem carteira em domicílios abaixo da linha de pobreza, observa-se um movimento semelhante: a proporção de sem carteira que contribui para a previdência sobe de $2 \%$ para $4,5 \%$ e a de trabalhadores por conta própria cai de $6 \%$ para $3 \%$.

Dado o grande peso que as contribuições representam para os trabalhadores pobres, se o BPC estivesse realmente induzindo as pessoas a não contribuir para a previdência pública, deveríamos estar vivenciando uma grande evasão das contribuições voluntárias tanto entre os trabalhadores sem carteira como entre os por conta própria. De modo semelhante, um aumento do assalariamento sem carteira - modo de evitar as contribuições - também deveria ter sido observado. No entanto, entre 1992 e 2005 , observou-se uma ligeira tendência de redução do assalariamento sem carteira — em 1992 o percentual de infor- 
malidade era de 51,9\%, atingiu 53,0\% em 1998, voltando a 51,7\% em 2003 e caindo para $50,4 \% \mathrm{em} 2004^{10}$. Esses dados não são conclusivos no que diz respeito à ausência de impacto do BPC sobre as contribuições previdenciárias, mas de modo algum provam o contrário.

Havendo imprevidência, tudo indica que sua magnitude será pequena em termos orçamentários. Portanto, os custos associados a isso serão provavelmente superados pelos benefícios diretos e indiretos que o BPC possa ter. $\mathrm{O}$ estudo de Reis e Camargo ${ }^{11}$, por exemplo, mostra que pensões e aposentadorias - que incluem o BPC - têm impactos positivos relevantes sobre a probabilidade de os jovens entre 15 e 21 anos freqüentarem a escola, um efeito até mesmo maior do que o relacionado à probabilidade de não participarem do mercado de trabalho nem estudarem. Esse tipo de impacto, muito importante para a redução da pobreza no longo prazo, pode justificar até mesmo certo ônus sobre o sistema previdenciário.

Em resumo, atualmente não há nenhuma evidência de que tenha ocorrido um processo generalizado de desestímulo à contribuição previdenciária devido à introdução do $\mathrm{BPC}$ e menos ainda que o efeito desse desestímulo sobre o orçamento previdenciário seja grande. Até que surjam estudos mais aprofundados, a crítica ao BPC deve ser tratada como mera especulação, sem respaldo científico confiável sobre a existência e as verdadeiras dimensões desse problema.

\section{RESTRIÇÃO FISCAL}

As transferências de renda são importantes para a redução da pobreza e da desigualdade no país. Sua utilização não tira o papel central das políticas fiscais e tributárias para a redistribuição de renda, instrumentos por meio dos quais o Estado se apropria de parte do queé produzido na sociedade de maneira mais ou menos progressiva ou regressiva. Nem contraria o peso da provisão universal de serviços públicos, como educação e saúde, na promoção da igualdade de oportunidades. Mas é com as transferências focalizadas que a redistribuição se dá de maneira mais direta, influindo não somente na desigualdade de condições, mas na própria desigualdade de resultados. Estima-se que, sozinhos, esses programas respondam por $23 \% \mathrm{da}$ queda da desigualdade de renda ocorrida entre 2001 e $2004^{12}$. Somados, o BPC e o Bolsa Família cobrem mais de 13 milhões de famílias de baixa renda no Brasil. Seus benefícios são indiscutíveis. O que dizer dos custos?

Em 2005, o gasto total com as transferências de renda no Brasil por meio do BPC e do PBF foi de aproximadamente o, $8 \%$ do Produto Interno Bruto (PIB). Apenas para referência, no mesmo ano o gasto financeiro federal com juros da dívida pública alcançou $6,7 \%$ do PIB.
[10] Ramos, L. "O desempenho recente do mercado de trabalho brasileiro: tendência, fatos estilizados e padrões espaciais". Ipea, 2007 (Texto para Discussão, n. 1.255).

[11] Reis,M.C.,Camargo,J.M.,op.cit.
[12] Ipea. "Nota técnica sobre a recente queda da desigualdade" "www. ipea.gov.br/sites/ooo/2/publicacoes/notastecnicas/notastecnicas9.pdf $>$. Acesso em 19/11/207. 
Isso significa que beneficiar diretamente 13 milhões de famílias de baixa renda custa pouco mais de um décimo do gasto com juros provocado pela política monetária, cujo número de beneficiários diretos é muito menor. É difícil dizer exatamente quão menor, pois a Pnad não só subestima severamente o recebimento de juros, dividendos e rendimentos de capital, como capta a informação em uma única categoria de renda. Mas, utilizando-se a desagregação dos "outros rendimentos" da Pnad como proposto em "Programas de transferência de renda no Brasil: impactos sobre a desigualdade"13, é possível estimar de modo grosseiro que metade dessas rendas foi recebida pelos 3\% mais ricos da população.

É evidente que o impacto indireto das políticas monetárias é relevante para todos, inclusive para os pobres, que se beneficiam da estabilidade macroeconômica. A comparação de programas sociais com medidas de política monetária é um tanto simplista e deve ser vista apenas como ilustrativa. O que realmente importa aqui é deixar claro que as restrições fiscais brasileiras não podem ser atribuídas aos programas de transferência focalizada e que é insensato impedir sua atual expansão ou criticar sua sustentação sob a justificativa de que causam pressão excessiva nos orçamentos públicos. Uma análise preliminar da relação de custo-benefício já é suficiente para indicar que os programas devem ser protegidos de tentativas de ajuste fiscal.

Já que existe uma restrição orçamentária, não seria melhor empenhar os recursos das transferências em investimentos? Seguramente as taxas de investimento público no país poderiam ser maiores, mas essa não é a maneira mais apropriada de apresentar a pergunta. Ela só faria sentido se houvesse uma rigidez completa em todo o orçamento público, isto é, se a única alternativa possível fosse decidir entre transferências ou investimento.

Não é o caso. O orçamento público é o resultado de uma série de escolhas. Grandes mudanças na alocação orçamentária podem ser inviáveis no curto prazo, mas indiscutivelmente existe uma margem de manobra para várias realocações de menor escala. É certo que a distribuição do orçamento é resultado de um jogo de forças políticas no qual a população mais pobre se encontra em posição desvantajosa: os pobres não são os principais beneficiários diretos de boa parte dos gastos públicos. Não significa, porém, dizer que eles não devam merecer atenção especial no orçamento. Fechar os olhos para isso implica perpetuar uma estratégia sustentada por décadas no Brasil e que se mostrou fracassada: a erradicação da pobreza seguindo a reboque dos investimentos em infra-estrutura e do crescimento da economia.

Opor as transferências a investimentos ignora a possibilidade de que ambos sejam complementares.Afinal, as transferências permitem que as famílias consumam mais, e aumento de consumo pode estimu- 
lar investimento. Se as pessoas querem comprar mais, os empresários vão querer produzir mais. Este círculo virtuoso pode ser alimentado ainda mais com investimentos em infra-estrutura. Portanto, transferências e investimentos podem andar de mãos dadas. Se de fato são ou não complementares ainda é algo a se descobrir.

Não raro as transferências focalizadas - PBF e BPC — são tratadas como pertencentes a uma grande categoria denominada "transferências", que engloba o restante do sistema previdenciário. Qualquer taxonomia tem caráter instrumental e, portanto, se justifica por seus propósitos; não se pode, assim, dizer que seja correto ou não usar a categoria antes que os objetivos da classificação sejam definidos. $\mathrm{O}$ fato é que as aposentadorias e pensões de caráter contributivo têm um peso orçamentário várias vezes maior do que o PBF e o $\mathrm{BPC}$ e, ao mesmo tempo, existe grande diferença entre as aposentadorias e pensões contributivas e os programas de transferência focalizados no que diz respeito ao público beneficiado diretamente por elas. Qualquer análise cautelosa do gasto público baseada em "transferências" deve ser feita levando em conta as distinções entre os vários tipos de programas. Indiscutivelmente equivocado é o procedimento de chegar a conclusões sobre o peso orçamentário do PBFe BPC a partir do gasto agregado na categoria das "transferências".

\section{CONCLUSÃo}

As políticas de transferência de renda vêm se consolidando como uma importante faceta do sistema de proteção social brasileiro. Os dois principais programas dessa natureza, o BPC e o Bolsa Família, têm se expandido consideravelmente nos últimos anos e gerado efeitos relevantes sobre os índices de pobreza e desigualdade no país, embora não estejam isentos de críticas ou problemas.

Os programas possuem mecanismos administrativos próprios de identificação e seleção de beneficiários. A pouca informação de que dispomos sobre seus resultados indica que uma parte grande dos beneficiários encontra-se acima dos níveis de corte delimitados pelos programas, mas ainda assim abaixo da linha de pobreza. São, portanto, erros de baixa intensidade. Em termos comparativos, os programas brasileiros atingem seu público-alvo de maneira aproximadamente tão eficaz quanto os programas de países vizinhos. É sempre importante buscar aprimorar os programas, mas é difícil dizer em que medida isso poderia trazer melhorias significativas em relação à situação atual, uma vez que parte dos desvios observados pode estar relacionada a flutuações cíclicas na renda das famílias e a erros intrínsecos ao processo de focalização, cujo controle pode ser extremamente custoso. 
A preocupação com a transmissão intergeracional da pobreza também distingue os programas. O Bolsa Família enfoca esse tema por meio de condicionalidades que pretendem promover investimentos em educação e saúde. Em parte pelas características do público beneficiário, o BPC não exige contrapartidas comportamentais. Porém resultados de pesquisas recentes apontam que a simples elevação das rendas causadas pelas transferências, mesmo sem condicionalidades, já parece ter impactos relevantes sobre a escolarização dos jovens nas famílias beneficiárias. Do ponto de vista moral, as condicionalidades exigem das famílias algo que já é determinado legalmente, portanto não se pode acusaro $\mathrm{PBF}$ de intrusividade na vida privada para além do que já determina a lei. Do ponto de vista da relação entre custo e benefício, o fato é que, até o momento, não se sabe exatamente quão necessárias são as condicionalidades e qual é o custo de seu controle.

O lado positivo dos programas analisados é indiscutível. Seus impactos sobre pobreza e desigualdade são visíveis. Já seu lado negativo não é claro. Primeiro, não há indicações de que as transferências afetem de modo substantivo (eindesejável) a participação no mercado de trabalho. Ao contrário, por razões que ainda precisam ser mais bem exploradas, essa participação em alguns casos é maior entre beneficiários. Segundo, não há nenhuma evidência sólida de que as transferências afetem de maneira relevante as contribuições previdenciárias e, menos ainda, de que esses impactos sejam expressivos para a previdência social. Havendo imprevidência, aparentemente sua magnitude será pequena em termos orçamentários. Finalmente, o ônus orçamentário dos programas focalizados não é grande. As transferências beneficiam cerca de um quarto das famílias brasileiras, mas seu custo está próximo de $1 \%$ do PIB. O nível atual de gasto com as políticas de transferência de renda, portanto, ainda pode ser expandido.

O que está em xeque ao discutir os programas de transferência de renda não é a necessidade desse tipo de política, mas, sim, o grau de solidariedade desejável para a sociedade brasileira. Praticamente todos os países que conseguiram erradicar a pobreza absoluta e reduzir expressivamente seus níveis de desigualdade possuem políticas de transferência de renda. Isso ocorre porque, mesmo em economias de renda alta, há uma parte da população que não consegue, por razões diversas, ter sua subsistência assegurada pelo trabalho.

MARCelo Medeiros é coordenador do Instituto de Pesquisa Econômica Aplicada (Ipea) no International Poverty Centre (IPC).

TATIANA BRITTO e FÁBIO SOARES são pesquisadores do IPC. 